\title{
Chronic thromboembolic pulmonary hypertension at the crossroad
}

\author{
Marius M. Hoeper \\ Affiliation: Dept of Respiratory Medicine and German Centre for Lung Research (DZL), Hannover Medical \\ School, Hannover, Germany.
}

Correspondence: M.M. Hoeper, Hannover Medical School, Carl-Neuberg-Str. 1, Hannover 30627, Germany. E-mail: hoeper.mariusamh-hannover.de

0 @ERSpublications

Balloon pulmonary angioplasty is an emerging therapeutic option for patients with inoperable CTEPH http://ow.ly/ubosj

Chronic thromboembolic pulmonary hypertension (CTPEH) is one of the few forms of pulmonary hypertension for which we have a clear and undisputed solution, i.e. pulmonary endarterectomy (PEA). In the vast majority of patients, PEA markedly improves or even cures the disease [1]. Over the years, surgeons have continuously improved their skills and are now reaching beyond the level of the subsegmental vessels. Patients, who would have been considered inoperable a couple of years ago, are now undergoing surgery and are surviving and doing well! In San Diego (CA, USA), considered the epicentre of the PEA universe, the in-hospital mortality for the most recent 500 surgeries in this field was $2.2 \%$ with no mortalities among the last 260 procedures; despite the patients presenting with more peripheral disease and more co-morbidities [2]. Recent reports from other centres are comparable [3, 4].

So, why even think about alternative therapies? Well, first of all, some patients are not operable, not even in the most experienced of centres. Occasionally, small-vessel disease dominates the picture and in such cases PEA is not a good option given a high risk of persistent pulmonary hypertension and a high mortality [5-7]. In fact, even after successful PEA, up to $31 \%$ of patients are afflicted by persistent or recurrent pulmonary hypertension [3, 8-10]. Other patients present with significant co-morbidities rendering the risks of major surgery unacceptably high, and some patients simply refuse to have their chest cut open, even when their doctors explain that this is their best option.

Alternative treatment options are emerging. Very recently, riociguat, a stimulator of the soluble guanylate cyclase, became the first drug approved for the treatment of CTEPH. However, this has been deemed exclusive for patients with inoperable disease and those with persistent or recurrent pulmonary hypertension after surgery [11-13].

And now balloon pulmonary angioplasty (BPA). The first report on this interventional approach to CTEPH was published in 2001 by FeINSTEIN et al. [14] from Boston MA, USA. The authors demonstrated considerable haemodynamic and functional improvements, but there were also major complications, most notably severe reperfusion oedema that required mechanical ventilation in several patients [14]. After that publication, one might have expected a surge of interest in BPA but it became surprisingly quiet, presumably as a result of major periprocedural complications. Only recently, a couple of centres, mostly from Japan, published their experiences with BPA for CTEPH [15-18]. Major, sometimes fatal, complications still occurred, these were largely reperfusion oedema and pulmonary bleeding, but with obvious decreasing frequency as the centres gained experience $[16,18]$. Our Japanese colleagues took several measures to reduce the periprocedural risks, among which limiting the intervention to one area at a time appeared to be the most important. Even if this means that repeated, usually three to five, interventions are

Received: Feb 242014 | Accepted: Feb 252014

Conflict of interest: Disclosures can be found alongside the online version of this article at www.erj.ersjournals.com

Copyright @ERS 2014 
required before the full therapeutic effect can be achieved. This careful approach appears to be the key to avoiding major complications. In addition, we have improved imaging technology and more advanced instrumentarium than 10 years ago. With all these factors coming together, the haemodynamic and functional outcomes reported from Japan are impressive and in fact not too different from what has been reported after PEA, including cases where pulmonary haemodynamics have normalised $[2,3,15,16,18]$.

In this issue of the European Respiratory Journal, FUKUI et al. [19] confirm and extend these findings. The authors' present data from cardiac magnetic resonance imaging studies that show reverse remodelling of the right ventricle after BPA, which is indicated by remarkable decreases in the size of the right heart chamber and muscle mass, in combination with improved contractility, haemodynamics and normalisation of the plasma brain natriuretic peptide (BNP) levels [19].

Thus, although the evidence is still limited, BPA is becoming a viable treatment option for selected patients with CTEPH. The questions, however, are which patients should be referred for BPA rather than to surgery and where should BPA be performed. The answers appear to be straightforward. Following the recommendations of current guidelines [20,21], patients with CTEPH should undergo a comprehensive diagnostic evaluation at an expert centre, where an interdisciplinary team of pulmonary hypertension experts, radiologists and PEA surgeons determine the treatment strategy. Surgery remains the preferred therapeutic option, which should be offered to all patients deemed operable. Naturally, novel and less invasive treatments stir enthusiasm, but we must not forget that the current evidence regarding the safety and efficacy of BPA comes from a few single-centre case series comprising less than 200 patients in total. Long-term follow-up data are missing and we don't have reliable information on the rate of restenosis or disease progression after BPA. In contrast, for PEA we have data from thousands of patients operated upon in centres all over the world, sometimes with follow-up periods of more than 10 years [2].

Hence, other treatment options should be seriously considered only when an experienced PEA surgeon, or the patient, declines surgery. In an ideal world, BPA would be performed exclusively in those centres also offering PEA surgery. Around the globe, these centres are already providing the highest possible standard of care for patients with CTEPH and many of these centres have already added BPA to their therapeutic portfolio. These centres are in the best position to generate large-scale, long-term data on the safety and efficacy of BPA and to determine which patients have the greatest benefit from this intervention.

In the real world, one does not need a crystal ball to anticipate that many interventional cardiologists or radiologists will be tempted to perform BPA themselves. This may be acceptable in expert pulmonary hypertension centres where close collaboration with PEA centres occurs and discussion arises for each individual patient prior to intervention; however it is certainly not in the best interest of our patients if it is performed anywhere else, at least not at the present stage where enthusiasm prevails over evidence.

Treatment of CTEPH is now at a crossroad and we need some wisdom not to go astray.

\section{References}

1 Jenkins DP, Madani M, Mayer E, et al. Surgical treatment of chronic thromboembolic pulmonary hypertension. Eur Respir J 2013; 41: 735-742.

2 Madani MM, Auger WR, Pretorius V, et al. Pulmonary endarterectomy: recent changes in a single institution's experience of more than 2,700 patients. Ann Thorac Surg 2012; 94: 97-103.

3 Mayer E, Jenkins D, Lindner J, et al. Surgical management and outcome of patients with chronic thromboembolic pulmonary hypertension: results from an international prospective registry. J Thorac Cardiovasc Surg 2011; 141: 702-710.

4 Camous J, Decrombecque T, Louvain-Quintard V, et al. Outcomes of patients with antiphospholipid syndrome after pulmonary endarterectomy. Eur J Cardiothorac Surg 2013 [In press DOI: 10.1093/ejcts/ezt572].

5 Archibald CJ, Auger WR, Fedullo PF, et al. Long-term outcome after pulmonary thromboendarterectomy. Am J Respir Crit Care Med 1999; 160: 523-528.

6 Dartevelle P, Fadel E, Mussot S, et al. Chronic thromboembolic pulmonary hypertension. Eur Respir J 2004; 23 : 637-648.

7 Lang IM, Pesavento R, Bonderman D, et al. Risk factors and basic mechanisms of chronic thromboembolic pulmonary hypertension: a current understanding. Eur Respir J 2013; 41: 462-468.

8 Freed DH, Thomson BM, Berman M, et al. Survival after pulmonary thromboendarterectomy: effect of residual pulmonary hypertension. $J$ Thorac Cardiovasc Surg 2011; 141: 383-387.

9 Corsico AG, D'Armini AM, Cerveri I, et al. Long-term outcome after pulmonary endarterectomy. Am J Respir Crit Care Med 2008; 178: 419-424.

10 Ghio S, Morsolini M, Corsico A, et al. Pulmonary arterial compliance and exercise capacity after pulmonary endarterectomy. Eur Respir J 2014; 43: 1403-1409.

11 Ghofrani HA, D’Armini AM, Grimminger F, et al. Riociguat for the treatment of chronic thromboembolic pulmonary hypertension. N Engl J Med 2013; 369: 319-329.

12 Ghofrani HA, Hoeper MM, Halank M, et al. Riociguat for chronic thromboembolic pulmonary hypertension and pulmonary arterial hypertension: a phase II study. Eur Respir J 2010; 36: 792-799.

13 Pepke-Zaba J, Jansa P, Kim NH, et al. Chronic thromboembolic pulmonary hypertension: role of medical therapy. Eur Respir J 2013; 41: 985-990. 
14 Feinstein JA, Goldhaber SZ, Lock JE, et al. Balloon pulmonary angioplasty for treatment of chronic thromboembolic pulmonary hypertension. Circulation 2001; 103: 10-13.

15 Kataoka M, Inami T, Hayashida K, et al. Percutaneous transluminal pulmonary angioplasty for the treatment of chronic thromboembolic pulmonary hypertension. Circ Cardiovas Interv 2012; 5: 756-762.

16 Sugimura K, Fukumoto Y, Satoh K, et al. Percutaneous transluminal pulmonary angioplasty markedly improves pulmonary hemodynamics and long-term prognosis in patients with chronic thromboembolic pulmonary hypertension. Circ J 2012; 76: 485-488.

17 Andreassen AK, Ragnarsson A, Gude E, et al. Balloon pulmonary angioplasty in patients with inoperable chronic thromboembolic pulmonary hypertension. Heart 2013; 99: 1415-1420.

18 Mizoguchi H, Ogawa A, Munemasa M, et al. Refined balloon pulmonary angioplasty for inoperable patients with chronic thromboembolic pulmonary hypertension. Circ Cardiovasc Interv 2012; 5: 748-755.

19 Fukui S, Ogo T, Morita Y, et al. Right ventricular reverse remodelling after balloon pulmonary angioplasty. Eur Respir J 2014; 43: 1394-1402.

20 Kim NH, Delcroix M, Jenkins DP, et al. Chronic thromboembolic pulmonary hypertension. J Am Coll Cardiol 2013; 62: D92-D99.

21 Galie N, Hoeper MM, Humbert M, et al. Guidelines for the diagnosis and treatment of pulmonary hypertension. Eur Respir J 2009; 34: 1219-1263. 